\title{
ALGUMAS LIMITAÇÕES DAS EXPLICAÇÕES DA ESCOLHA RACIONAL NA CIÊNCIA POLÍTICA E NA SOCIOLOGIA*
}

\section{Patrick Baert}

Introdução

Os enfoques economicistas e individualistas da vida social eram uma dasbêtes noires $\underline{\underline{I}}$ do projeto sociológico de Durkheim. Parte da constituição da nova disciplina da Sociologia era distingui-la claramente da Psicologia e da Economia, não apenas em termos de objeto, mas também em termos de abordagem teórica. Ao contrário de análises individualistas, a sociedade era considerada por Durkheim como uma entidade sui generis, e não apenas um mero agregado dos seus componentes. Além disto, atitudes de cálculo racional foram consideradas como limitadas a esferas particulares da vida social, e mesmo nos casos em que os cálculos eram predominantes, uma precondição para a sua existência era identificada nas normas sociais e em valores compartilhados.

A Sociologia tem sido dominada há muito tempo por essa perspectiva durkheimiana. A versão atenuada desta abordagem vê o raciocínio sociológico como algo simplesmente estranho ao quadro analítico de indivíduos que racionalmente perseguem seus interesses. A versão extrema pressupõe que a razão é, nos termos de John Wilmot, "um ignus fatuus da mente humana", isto é: sob o nível superficial da ação racional subjaz o nível mais profundo e fundamental das estruturas sociais não admitidas. Esta perspectiva, defendida em qualquer de suas versões, permeou a Sociologia do século XX: há um consenso entre teóricos tão diferentes como Parsons, Dahrendorf, Garfinkel, Bourdieu e Giddens com respeito à irredutibilidade da vida social à lógica econômica. Mesmo teóricos da ação weberiana, que têm sido tradicionalmente hostis a explicações de tipo holístico, fazem questão de se afastar de qualquer tipo de reducionismo economicista. A emergência da teoria da escolha racional no curso dos anos 1980 é portanto surpreendente e revolucionária, pois ela nada mais é do que a invasão do homem econômico. Representa o último assalto imperialista da economia na Sociologia: a subordinação do homo sociologicus ao homo economicus. 
Alguém poderia argumentar, é claro, que a expansão do homem econômico já ocorreu no passado. Afinal de contas, a teoria política de Hobbes se baseava pesadamente na visão de que o mundo era habitado por um conjunto de agentes racionais, orientados somente pelos seus interesses; e Adam Smith empregou ocasionalmente a lógica econômica para explicar a ação política. As reformas utilitaristas do início do século XIX partiram da lógica econômica, postulando que em todos os lugares e épocas as pessoas tenderam a trocar a dor pelo prazer e que as instituições deviam ser direcionadas por estes princípios utilitaristas. Alguns teóricos da escolha racional vão ainda mais além e defendem que as metodologias de Tocqueville e Marx na verdade ocultam perspectivas da escolha racional (por exemplo, Boudon,1982; Elster, 1985). 1

No entanto, apenas recentemente a abordagem econômica foi empregada de forma tão sofisticada para capturar os diversos aspectos da vida social, abrangendo desde a freqüência à igreja e os casamentos até as situações de guerra e os padrões de suicídio (por exemplo, Arrow, 1951; Downs, 1957; Olson, 1965; Becker, 1976; Coleman, 1990). Tanto a sofisticação como a ampla aplicabilidade do raciocínio econômico corrente são devidas, parcialmente, à emergência e ao desenvolvimento da teoria dos jogos. A teoria dos jogos objetiva trabalhar, por meio de conceitos, situações nas quais os indivíduos tomam decisões considerando as conseqüências das decisões tomadas por outros (ver, por exemplo, Kreps, 1990). Graças à sua sofisticação, tem apresentado diversas descobertas que contrariam a intuição - por exemplo, a descoberta de que em certas circunstâncias as pessoas podem ficar em pior situação agindo na busca de seu próprio interesse. Dada a sua natureza abstrata, a teoria dos jogos se presta a uma ampla aplicação, encorajando ainda mais a sua popularidade.

Neste artigo, analiso algumas limitações das abordagens econômicas e da sua aplicação a fenômenos não econômicos. As duas primeiras seções ajudam a montar o quadro geral da abordagem. Na primeira, discuto as premissas que estão por trás da abordagem econômica, destacando o que os seus defensores compreendem como racionalidade e comportamento racional. $\mathrm{Na}$ segunda seção, discuto alguns exemplos de aplicações da teoria da escolha racional na Ciência Política e na Sociologia, partindo dos trabalhos de Downs, Olson, Becker e Coleman. Na terceira seção, tento discutir as principais limitações da abordagem econômica. Antes de fazê-lo, no entanto, detalho de forma breve o que será discutido exatamente e, mais importante, o que não será discutido.

$\mathrm{O}$ artigo enfoca a abordagem econômica, ou o que nos dias de hoje se denomina normalmente de "teoria da escolha racional". A teoria da escolha racional é definida como a teoria sociológica que se propõe a explicar o comportamento social e político assumindo que as pessoas agem racionalmente. Apesar de em si não gerar controvérsia, esta definição leva a um conjunto de conseqüências.

Em primeiro lugar, trato da teoria da escolha racional como a teoria que se propõe a estudar fenômenos políticos e sociais, e não econômicos. Algumas das críticas que o artigo levanta podem também ser válidas às análises da teoria da escolha racional na economia, mas prefiro deixar aos economistas o julgamento da validade dos pontos aqui levantados na sua disciplina.

Segundo, a teoria da escolha racional (ao menos de acordo com a definição trabalhada aqui) deve ser distinguida de reflexões filosóficas com respeito à racionalidade e à escolha racional. Estas visões filosóficas em alguns casos informam a teoria da escolha racional, mas esta certamente não incorpora todas aquelas reflexões. Portanto, minhas críticas contra a teoria da escolha racional não são necessariamente críticas às obras filosóficas de Elster e Hollis (por exemplo, Elster, 1979, 1983, 1986a, 1986b e 1989; Hollis, 1988 e 1994).

Em terceiro lugar, a teoria da escolha racional é distinta da teoria da decisão. A teoria da decisão é uma teoria normativa e informa o que uma determinada pessoa deveria fazer se ele ou ela fosse racional. A teoria da escolha racional às vezes utiliza desenvolvimentos da teoria da decisão, mas esta não será analisada aqui e as citações a ela 
ocorrerão apenas na medida do necessário para o desenvolvimento da crítica à primeira.

Em quarto lugar, teóricos da escolha racional desenvolvem teorias sociológicas e tentam explicar e prever os padrões de comportamento de um determinado grupo de pessoas. A teoria da escolha racional não deve ser entendida como uma teoria que explica ou prevê simplesmente o comportamento individual. Por exemplo, alguns teóricos da escolha racional se propõem a explicar e prever os padrões de voto e não o voto de cada (ou qualquer) indivíduo.

\section{As explicações da escolha racional}

Para obter uma maior clareza, é interessante discutir em detalhes as mais importantes características das explicações da escolha racional. $²$ Apesar da existência de uma miríade de versões da teoria da escolha racional, a maioria dos seguidores considera as seguintes noções-chave: (a) a premissa da intencionalidade; (b) a premissa da racionalidade; (c) a distinção entre informação completa e incompleta e, no caso da última, a diferença entre risco e incerteza; (d) a distinção entre ação estratégica e ação interdependente. Tratemos de cada uma separadamente.

\section{Ação intencional e conseqüências não intencionais}

As explicações da escolha racional são um subconjunto das explicações intencionais. As explicações intencionais não estipulam apenas que os indivíduos agem intencionalmente, mas tentam dar conta das práticas sociais fazendo referência a finalidades e objetivos. Explicações intencionais são geralmente acompanhadas da procura de conseqüências não intencionais (os assim chamados "efeitos de agregação") nas ações intencionais das pessoas. Ao contrário de formas funcionalistas de explicação, as conseqüências não intencionais das práticas sociais não são empregadas para explicar a persistência das mesmas práticas.
Teóricos da escolha racional dão especial atenção a dois tipos de conseqüências negativas não intencionais, ou "contradições sociais": a "contrafinalidade" e as soluções subótimas. A "contrafinalidade" se refere à chamada "falácia da composição", que ocorre toda a vez que alguém age de acordo com a falsa premissa de que "o que é possível para cada indivíduo em circunstâncias especiais é necessariamente possível para todos os indivíduos nestas circunstâncias" (Elster, 1978, pp. 106 e ss., e 1989, pp. 95 e ss.). Tomemos o exemplo de Sartre sobre o desmatamento: cada camponês pretende conseguir mais terra cortando árvores, o que leva ao desmatamento e à erosão e, como conseqüência, a que os camponeses tenham menos terra cultivável do que tinham no início do processo (Sartre, 1960, pp. 232 e ss.). Soluções subótimas se referem a indivíduos que, enfrentando escolhas interdependentes, escolhem uma estratégia sabendo que os demais indivíduos também vão escolhê-la e sabendo também que todos poderiam obter ao menos o mesmo se outra estratégia tivesse sido adotada (Elster, 1978, pp. 122 e ss.). Utilizando novamente o exemplo dos camponeses de Sartre, diríamos que um camponês adota um comportamento subótimo quando está ciente da possibilidade do resultado agregado mas, mesmo assim, compreende que, qualquer que seja a decisão dos outros, derrubar árvores é do seu interesse. $\mathrm{O}$ chamado dilema do prisioneiro é um claro exemplo de comportamento subótimo com duas pessoas envolvidas.

\section{Racionalidade}

As explicações da escolha racional são um subconjunto das explicações intencionais que atribuem, como o nome sugere, racionalidade à ação social. Racionalidade, neste contexto, significa que, ao agir e interagir, os indivíduos têm planos coerentes e tentam maximizar a satisfação de suas preferências ao mesmo tempo que minimizar os custos envolvidos. A racionalidade pressupõe, portanto, a "premissa da conectividade", isto é, o indivíduo envolvido é capaz de estabelecer um completo ordenamento das alternativas. Desta ordenação de preferências os cientistas sociais podem inferir uma "função de utilidade", que atribui um número a cada opção de acordo com a sua posição nessa ordenação de preferências. Para que uma pessoa seja 
considerada racional, sua ordenação de preferências precisa ainda preencher um conjunto de requisitos. O princípio da transitividade é um exemplo óbvio deste tipo de precondição: a preferência de $X$ sobre $Y$ e deste sobre $Z$ deve significar uma preferência de $X$ sobre Z $Z$. Caso tanto a conectividade como a transitividade sejam obtidas, os teóricos da escolha racional sustentam "uma ordenação fraca de preferências" (Arrow, 1951, pp. 13 e ss.).

Explicações da escolha racional tentam dar conta do comportamento individual fazendo referência às convicções subjetivas e às preferências de um certo indivíduo e não às condições objetivas e oportunidades daquele indivíduo. É possível para alguém, portanto, agir de forma racional baseado em convicções falsas vis-à-vis os melhores meios de atingir seus objetivos ou desejos. No entanto, para que alguém seja considerado racional, deve agrupar, na medida do possível, informação suficiente para tornar sólidas suas convicções. A obtenção exagerada de informações pode, é óbvio, também ser um sinal de irracionalidade, especialmente se a situação requer uma certa urgência. A análise prolongada de possíveis estratégias quando um exército é confrontado com um ataque militar iminente, por exemplo, teria conseqüências desastrosas.

\section{Incerteza e risco}

Até o momento se assumiu que as pessoas têm "informações perfeitas" sobre os efeitos de suas ações, mas na realidade as pessoas muito freqüentemente têm apenas "informações imperfeitas" com respeito à relação entre um conjunto particular de ações e seus resultados. Alguns teóricos assumem a posição extrema de afirmar que não há situações da vida real nas quais as pessoas sejam capazes de partir de informações perfeitas porque, como Burke afirmou dois séculos atrás, "você nunca pode planejar o futuro pelo passado". Os teóricos da escolha racional conceituam informação imperfeita por meio da distinção entre "incerteza" e "risco", introduzida pela primeira vez por Keynes (1921) e Knight (1921). Enfrentando risco, as pessoas são capazes de atribuir probabilidades aos vários resultados, ao passo que, confrontadas com situações de incerteza, não são capazes de fazê-lo. Os teóricos da escolha racional tendem a se concentrar em situações de risco por duas razões: eles podem afirmar que as situações de incerteza não existem; ou podem sustentar que se elas existissem a teoria da escolha racional seria incapaz de dar conta da ação dos indivíduos. A teoria da escolha racional, enfim, assume que as pessoas são capazes de calcular a "utilidade esperada" ou o "valor esperado" de cada ação quando enfrentam risco. Para obter a "utilidade esperada" é necessário, primeiro, multiplicar para cada resultado, $X_{i}$, a sua utilidade $U_{i}$ pela sua probabilidade de ocorrência $P_{i}$. A utilidade esperada, então, corresponde à soma destas multiplicações: $U_{1} \cdot P_{1}+U_{2} \cdot P_{2}+\ldots+U_{i} \cdot P_{i}+\ldots+$ $U_{n} \cdot P_{n}$ (com $n$ representando o número de possíveis resultados). $\underline{3}$

\section{Escolhas interdependentes e estratégicas}

Com exceção dos dois tipos de "contradições sociais" descritas anteriormente (que são indicativas de escolhas interdependentes ou estratégicas), a análise se concentrou, até o momento, em "escolhas paramétricas". Escolhas paramétricas se referem às escolhas que indivíduos devem tomar quando confrontados com um ambiente independente das suas escolhas. Comportamento subótimo e contrafinalidade são exemplos de escolhas estratégicas nas quais os indivíduos levam em conta as escolhas de outros antes de decidir sua própria linha de ação. Pessoas que compram e vendem ações na bolsa de valores, para dar um outro exemplo, tendem a considerar as escolhas dos outros antes de tomarem suas próprias decisões. No interior da teoria da escolha racional, a teoria dos jogos trata da formalização de escolhas estratégicas ou interdependentes por meio da construção de modelos ideais típicos. Estes jogos antecipam a decisão racional de cada jogador em jogos nos quais os demais jogadores também tomam decisões e em que cada jogador precisa levar em conta as escolhas dos outros. 


\section{Exemplos de aplicações da escolha racional}

Tendo as noções básicas da teoria da escolha racional em mente, apresento agora exemplos de suas aplicações na Sociologia e na Ciência Política. Selecionei para este propósito quatro livros que, em momentos diferentes, contribuíram para uma abordagem econômica mais sofisticada e aumentaram a sua aceitação na Ciência Política e na Sociologia. Um dos primeiros livros de teoria da escolha racional a explorar aplicações na Ciência Política foi An economic theory of democracy (1957), de Anthony Downs. O livro The logic of collective action, de Mancur Olson Jr. (1965), tentou utilizar a mesma perspectiva para compreender organizações. Em Economic approach to human behavior (1976), Gary Becker agrupou artigos que tentavam demonstrar a ampla aplicabilidade do enfoque econômico a uma grande variedade de fenômenos, abrangendo desde consumo de drogas até casamentos. Finalmente, Foundations of social theory (1990), de James Coleman (1990), é uma contribuição à teoria social de uma perspectiva da teoria da escolha racional. Cada uma dessas obras será discutida separadamente.

An economic theory of democracy, de Anthony Downs

A premissa de Downs é que políticos e eleitores agem racionalmente. As motivações dos políticos são desejos pessoais, tais como renda, prestígio e poder derivados dos cargos que ocupam. Como estes atributos não podem ser obtidos sem que eles sejam eleitos, as ações dos políticos têm por objetivo a maximização do apoio político e suas políticas são orientadas meramente para este fim. Os eleitores estabelecem preferências entre partidos competidores baseados em uma comparação entre: (a) a "renda de utilidade" das atividades do atual governo e (b) a renda de utilidade se os partidos de oposição estivessem no governo. A escolha de um partido pelos eleitores toma como base esta ordem de preferências, assim como características do sistema eleitoral. Em um sistema de dois partidos, os eleitores simplesmente votam no partido que preferem. Em um sistema multipartidário, no entanto, os eleitores têm de levar em conta a preferência dos outros eleitores. Por exemplo, se o partido que ele ou ela preferem não tem chances de vencer, então ele ou ela votam em outro partido que pode ter a possibilidade de manter o partido que ele ou ela têm mais aversão fora do poder.

Por sua vez, argumenta Downs, os governos ganham votos com gastos públicos e os perdem se aumentam os impostos. Eles continuarão aumentando o gasto até quando o ganho marginal de votos decorrente dos gastos igualar à perda marginal de votos pelo aumento de impostos necessário para financiar aqueles gastos. $\mathrm{O}$ ganho ou a perda de votos dependem da renda de utilidade de todos os eleitores e das estratégias dos partidos de oposição. O trabalho de Downs marcou a penetração da abordagem econômica em algumas áreas da Ciência Política.

The logic of collective action, de Mancur Olson Jr.

O que Downs conseguiu fazer na Ciência Política, Olson fez na teoria das organizações. Olson trabalhou com as organizações que tratam dos interesses comuns de seus membros. Todos os membros de um sindicato, por exemplo, têm o interesse comum em melhores condições de trabalho ou maiores salários (pp. 6 e ss.). O autor enfocou os "bens públicos", isto é, aqueles bens que, uma vez alcançados por uma ou várias pessoas em um grupo, não podem ser negados ou retirados dos demais membros do grupo (pp. 14 e ss.). Nestes casos, observou o seguinte problema: suponha-se que todos os membros de um grande grupo estão interessados na obtenção de um determinado bem público. A obtenção do bem, no entanto, consome tempo e energia, e portanto, cada membro não tem interesse em contribuir com seu esforço pessoal e prefere deixar que outros membros o façam, já que, uma vez obtido o bem, ele estará disponível para todos. Além disto, em grupos grandes o esforço individual freqüentemente tende a não fazer diferença. No entanto, se todos agirem desta forma, ninguém obterá o bem público. Portanto, apesar de ser do interesse de todos obter o bem, o grupo não necessariamente o obtém. Isto explica por que grupos grandes tendem a empregar incentivos e sanções 
para fazer com que as pessoas contribuam para a obtenção dos bens públicos (pp. 22-52).

\section{Economic approach to human behavior, de Gary Becker}

Este livro encerra um conjunto de artigos com uma introdução provocativa e de destaque. Todo o trabalho é informado pela convicção de que o que distingue a Economia de outras disciplinas das ciências sociais não é o objeto, mas a abordagem (pp. 3-5). O objetivo de Becker é demonstrar que o que ele denomina de "abordagem econômica" é extremamente poderosa e pode ser aplicada para um amplo conjunto de fenômenos. Outros autores têm demonstrado a utilidade dessa abordagem para a explicação da vida econômica, mas Becker toma como sua a tarefa de mostrar a aplicabilidade da abordagem econômica a um amplo leque de comportamentos não econômicos. Ele é o mais claro expoente do "imperialismo econômico", pois vai longe o bastante para afirmar que a abordagem econômica "[...] fornece uma valiosa estrutura de conceitos unificada para o entendimento de todoo comportamento humano" (pp. 14; grifo no original).

Becker propõe as seguintes premissas como centrais para a "abordagem econômica": primeiro, as preferências dos indivíduos são relativamente estáveis e não diferem substancialmente entre diferentes culturas e sociedades; segundo, as pessoas tentam maximizar suas preferências tendo como base uma quantidade ótima de informação; em terceiro lugar, os mercados existem e coordenam as ações das pessoas envolvidas e a consistência mútua de seus comportamentos (pp. 5-7 e 14). A força do trabalho de Becker está na sofisticação técnica do tratamento do seu material empírico.

Foundations of social theory, de James Coleman

Assim como Social systems de Parsons (1951), Social theory and social structure de Merton (1957) eConstitution of society de Giddens (1984), Foundations of social theory objetiva desenvolver um tratado de teoria social. Como Merton, Coleman baseia sua teoria em pesquisa empírica, o que objetiva demonstrar a utilidade de seu programa de pesquisa. Como Parsons e Giddens, o autor tenta transcender à oposição tradicional entre os níveis macro e micro da sociedade (pp. 6 e ss.). A sua contribuição à teoria social opera em três níveis: (a) tenta explicar como as propriedades do nível sistêmico afetam o nível individual; (b) tenta dar conta do que ocorre no nível individual, e (c) trabalha as formas pelas quais as ações das pessoas afetam o nível sistêmico (pp. 8 e ss.). A idéia básica é simples: a cultura gera valores específicos nas pessoas envolvidas, que agem na busca destes valores e, fazendo isto, afetam a sociedade. A elaboração aprofundada desta proposição é complexa e tomaria quase mil páginas.

Especialmente importante para a sua pesquisa é a noção de ação racional e direcionada a fins. Para Coleman, as pessoas não apenas agem intencionalmente; elas também escolhem ações ou bens que maximizem sua utilidade (p. 14). O autor apresenta duas razões para explicar por que toma como premissa que as pessoas tentam maximizar suas preferências. Primeiro, uma teoria que assuma que as pessoas maximizam sua utilidade tem maior poder de previsão do que uma teoria que simplesmente postule intencionalidade. Segundo, assumir que as pessoas maximizam sua utilidade aumenta a simplicidade da teoria (pp. 18-19). Igualmente importante é a noção do autor de que a ação direcionada a fins afeta o nível macro. Coleman presta atenção especial no papel das conseqüências não intencionais. As pessoas agem direcionadas a fins, mas podem ser produzidos resultados que elas não buscavam ou que não conseguiam prever. Algumas vezes estes efeitos podem até contrariar as intenções iniciais (pp.19 e ss.).

\section{Problemas com a teoria da escolha racional}

\section{$A$ distinção entre agir como se fosse racional e agir racionalmente}

Os teóricos da escolha racional freqüentemente defendem suas teorias argumentando que a idéia de que as pessoas agem racionalmente é confirmada por descobertas empíricas. Mas é importante entender o que esses teóricos têm em mente com a noção de corroboração ou 
confirmação empírica. Para justificar sua perspectiva, eles se referem com freqüência ao fato de que o modelo que resulta de sua perspectiva permite previsões precisas sobre as ações das pessoas e sobre os efeitos destas ações. Por trás deste raciocínio está a premissa epistemológica de que a validade de uma teoria depende de seu poder de previsão.

Entretanto, a coerência entre o modelo e a realidade não é suficiente para corroborar as teorias da escolha racional que formam a base do modelo. Em primeiro lugar, desenvolvimentos recentes na filosofia da ciência enfraquecem a noção de que a força de uma teoria depende do seu poder de predição. Dado que os sistemas sociais tendem a ser abertos, a corroboração e a falsificação de uma teoria não são relevantes porque elas podem ser devidas a outros mecanismos que podem potencialmente intervir. ${ }^{4}$ Em segundo lugar, há uma distinção entre agir racionalmente e agir como se fosse racional. Da observação da congruência entre o modelo e a realidade (e do poder de predição resultante da teoria), pode ser legítimo inferir que as pessoas geralmente agem de acordo com os princípios básicos da racionalidade, mas seria errado tomar tal congruência como evidência empírica de que as pessoas normalmente agem racionalmente. Para que os indivíduos ajam como se eles fossem racionais não há necessidade de que ocorra nenhum processo de decisão racional remotamente similar ao atribuído aos indivíduos pela teoria da escolha racional.

Tomemos por exemplo uma teoria rival $T^{\prime}$, segundo a qual (a) os indivíduos tacitamente adquirem habilidades e práticas e (b) estas habilidades e práticas são, em média, racionais. Se $M$ é o modelo derivado da teoria da escolha racional e $M^{\prime}$ o modelo derivado da teoria rival, então $M$ é idêntico a $M^{\prime}$ porque a teoria da escolha racional e $T^{\prime}$ diferem apenas na forma como levam em conta a ação humana, como cálculo consciente ou conhecimento tácito. Isto significa, entretanto, que as mesmas evidências empíricas que foram utilizadas para apoiar a teoria da escolha racional podem ser igualmente usadas para demonstrar a teoria rival $T^{\prime}$, ou, em outras palavras: se $M$ fornece predições acuradas, então $M^{\prime}$ também o fará.
Problemas com o contra-argumento "externalista"

Alguns teóricos da escolha racional podem, é claro, responder que sua versão particular da teoria da escolha racional é uma versão "externalista" (por exemplo, Friedman, 1953; Becker, 1976; Posner, 1980). Ao contrário dos "internalistas", os externalistas abandonam a premissa da intencionalidade. Becker, por exemplo, afirma que sua abordagem econômica "[...] não considera que as unidades de decisão sejam necessariamente conscientes de seus esforços para maximizar, ou sejam capazes de verbalizar ou, ao contrário, descrevam as razões para os padrões sistemáticos no seu comportamento" (Becker, 1976, p. 112). Esta postura externalista introduz uma perspectiva teórica que afirma que: (a) as pessoas geralmente agem racionalmente e (b) elas fazem isto porque adquirem tacitamente habilidades e práticas (que têm uma racionalidade) ou porque estas habilidades e práticas são produto de um cálculo consciente.

Vejo três problemas neste contra-argumento. Primeiro, dado que o requisito do (necessário) cálculo racional foi abandonado, esta postura externalista $\left(T^{\prime \prime}\right)$ torna-se muito similar às perspectivas rivais como $T^{\prime}$; desse modo, seria tão justificável chamar $T^{\prime \prime}$ de uma perspectiva da escolha racional quanto batizar $T^{\prime}$ como tal. A única justificativa para isto talvez seja que $T^{\prime \prime}$ deixa aberta a possibilidade de as habilidades e práticas das pessoas serem produto de cálculo racional, ao passo que $T^{\prime}$ as vê exclusivamente em termos de conhecimentos adquiridos tacitamente. Entretanto, uma vez que se deixa o domínio das teorias artificiais (como T), é possível notar que as perspectivas teóricas rivais (que partem de conhecimento tácito ou prático) nem mesmo excluem a possibilidade de intencionalidade. Elas simplesmente negam a regularidade ou o caráter típico da sua ocorrência.

Tomemos por exemplo a perspectiva de Bourdieu de teoria social. Bourdieu (1977, p.199) sustenta que: (a) o "habitus" das pessoas é ajustado às condições objetivas nas quais elas estão situadas e (b) o "habitus" não é tipicamente adquirido de forma consciente. Bourdieu não exclui o fato de que o "habitus" é incorporado ocasionalmente de forma 
consciente, mas apenas nega que esta seja a norma. Não pretendo defender a identidade entre o formato explicativo de Bourdieu e o dos externalistas, mas afirmar apenas que eles não são substancialmente diferentes com respeito à premissa de que as práticas sociais são um produto do cálculo consciente. Colocando de forma concisa, não há razões óbvias que justifiquem incluir a perspectiva externalista, mas não a de Bourdieu, dentre as perspectivas da escolha racional. Entretanto, é plenamente desprovido de sentido chamar a teoria de Bourdieu de teoria da escolha racional, e portanto é igualmente absurdo denominar a visão dos externalistas de teoria da escolha racional.

Em segundo lugar, o poder de explicação da perspectiva externalista é pequeno. Deixem-me clarificar isto por meio da noção weberiana de que tanto a "adequação causal" como a "adequação de sentido" são condições sine qua non para a validade de uma explicação social. Enquanto a adequação causal é preenchida, se e somente se, a explicação apresentada é apoiada por regularidades observadas, a adequação de sentido é preenchida, se e somente se, a explicação dá sentido e torna inteligíveis as regularidades observadas. Dado que as ciências sociais lidam com sistemas abertos, não atribuo tanta importância às conjunções regulares como Max Weber. Da mesma forma, não pretendo me comprometer com as especificações posteriores do autor no que diz respeito à obtenção da adequação de sentido a partir da Verstehen. É muito difícil, no entanto, negar sua visão geral de que a adequação de sentido é essencial nas explicações na Ciência Política e na Sociologia. O ato de explicar é, em realidade, o esforço de tornar os fenômenos observados inteligíveis. É exatamente neste ponto que as visões externalistas não vão muito longe. Apesar de avançarem muito na adequação de causalidade, os externalistas são fracos na adequação de sentido, pois não querem se comprometer a explicar como os padrões observados surgiram.

Não é surpreendente, portanto, que aqueles que se posicionam no campo externalista tendam a invocar intencionalidade e noções relacionadas (como conhecimento e previsão) quando discutem os resultados de suas pesquisas. Tomemos por exemplo Becker (um externalista autodeclarado), que defende que as pessoas vivem um estilo de vida não salutar, não por ignorância de suas conseqüências, mas porque outras coisas são mais importantes para elas do que maximizar a sua expectativa de vida. Fumar muito e trabalhar demais "[...] seriam decisões desaconselháveis se o único objetivo fosse uma longa vida, mas considerando que existem outras metas, elas poderiam ser informadas e neste sentido sensatas" (Becker, 1976, p. 114; destaque meu). Caso um autor se apege a uma visão externalista (à qual Becker adere em matéria de teoria), noções como as de "objetivo", "decisões informadas" e "decisões sensatas" devem ser excluídas. No entanto, considerando que no nível da adequação de sentido o externalismo é fraco, externalistas autodeclarados têm apenas duas opções: eles podem se firmar à doutrina externalista, e então não conseguem dizer nada além de reafirmar que as pessoas geralmente agem como se fossem racionais, ou eles podem pular de volta para o internalismo na discussão de seus resultados. Não admira que a maioria, como Becker, é levada à segunda opção (apesar de suas já mencionadas dificuldades).

\section{Explicações a posteriori}

Os teóricos da escolha racional, sejam eles externalistas ou internalistas, tendem a dar sentido às práticas sociais atribuindo a elas racionalidade expost facto. Na verdade, eles consideram que sua tarefa é demonstrar que as práticas sociais que são irracionais prima facie são na verdade racionais (ver, por exemplo, Coleman, 1990, p. 18; Becker, 1976, pp. 13-14). Quanto mais as práticas parecem irracionais, mais significativo é o esforço de demonstrar que elas são racionais. Por exemplo, apesar de irracional à primeira vista, alguns psicólogos sociais, como Brown, utilizam a teoria dos jogos para demonstrar que o comportamento de pânico é, afinal de contas, racional (Brown, 1965; ver também Coleman, 1990, pp. 203-211). Exemplos na Sociologia incluem as tentativas de mostrar que os padrões de casamento e de comportamento criminoso operam de acordo com uma lógica econômica (Becker, 1976, pp. 39-88 e 205-250). É interessante notar a analogia com o início do funcionalismo. Se o funcionalismo tendia a atribuir retrospectivamente racionalidade social a 
práticas que eram prima facieirracionais, as explicações da escolha racional tentam dar sentido a práticas atribuindo racionalidade individual ex post facto. De forma similar à tendência do funcionalismo em seu período inicial de legitimar as práticas existentes, a teoria da escolha racional é invocada freqüentemente como deus ex machina, sugerindo que as pessoas vivem no "melhor de todos os mundos possíveis" de Leibniz ou Voltaire (ou ao menos no mais racional).

Neste sentido, há problemas sérios relacionados com esta teorização feita a posteriori. O simples fato de que as práticas possam ser agrupadas sob um comportamento racional não representa a comprovação ou validação da teoria da escolha racional. A maioria das práticas, se não a sua totalidade, pode ser reconstruída desta forma, especialmente porque os teóricos da escolha racional tendem a atribuir preferências e convicções que fazem encaixar a sua teoria nos seus projetos de pesquisa. Os teóricos da escolha racional, na verdade, se baseiam em raciocínios ex post facto para imunizar suas teorias contra potenciais falsificações. Em primeiro lugar, quando confrontam o fato de que as pessoas nem sempre ajustam seu comportamento a novas oportunidades, eles tendem a defender que "[...] como o ajustamento não ocorre sem custos, pode ser racional postergá-lo até que a pessoa saiba com certeza que a mudança é durável" (Elster, 1986b, p. 24). Em segundo lugar, confrontados com o fato de que as pessoas freqüentemente contribuem mais para a obtenção de bens públicos do que o previsto pela teoria, os teóricos da escolha racional tendem a argumentar que os indivíduos envolvidos simplesmente superestimam o impacto de suas próprias ações (Hardin, 1982, pp. 115 e ss.).

Em terceiro lugar, ocorre o bem conhecido "paradoxo do voto", isto é, dado que votar toma tempo e que cada voto, individualmente, com muita probabilidade não será decisivo, a teoria da escolha racional esperaria que as pessoas não fizessem o esforço para votar. No entanto, um número significativo de pessoas vota. Ao invés de tratar isto como uma falsificação, os teóricos da escolha racional tendem a incluir este fenômeno não intuitivo em sua narrativa racional. Para eles, as pessoas votam porque superestimam o impacto de seus votos ou porque votar dá a elas alguma satisfação psicológica não considerada por teóricos da escolha racional mais antigos como Downs. Elas obtêm satisfação psicológica expressando fidelidade a um sistema político ou contribuindo para um empreendimento potencialmente bem-sucedido (Riker e Ordershook, 1973, p. 62; Hinich, 1981; Schwartz, 1987; Coleman, 1990, pp. 290 e ss.).

Em suma, existem dois problemas com este tipo de teorização a posteriori. O primeiro deles é que ela se apóia em premissas a posteriori que não são validadas empiricamente (por exemplo, a premissa de que as pessoas superestimam o impacto de suas ações). Em segundo lugar, ela acomoda observações mutuamente exclusivas (por exemplo, comportamento regulado e não regulado; ação cooperativa e defecção; abstenção e voto), que, portanto, não permitem falsificação. Embora os teóricos da escolha racional tendam a se situar na tradição dos estudos que pregam a possibilidade de falsificação, eles não admitem que reconstruções a posteriori não servem para confirmar empiricamente a sua teoria.

\section{Racionalidade e cultura}

Muitos teóricos da escolha racional tendem a ignorar ou a igualar a diversidade cultural. Alguns deles afirmam que as preferências são estáveis entre culturas (Becker, 1976, pp. 5 e ss.), o que se encaixa bastante bem com a tendência de atribuir preferências aos sujeitos envolvidos sem checar empiricamente se isto é justificável (se as preferências são estáveis, então o pesquisador pode confiar em si mesmo para atribuir preferências a outros).

Várias justificativas insatisfatórias são dadas para a afirmação de que as preferências são estáveis. A mais antiga delas é a afirmação de que a economia sabe pouco a respeito da formação das preferências, e que isto é uma razão suficiente para se assumir as preferências como invariantes (Becker, 1976, p. 5). O absurdo deste argumento é óbvio: a fragilidade da abordagem (sua inabilidade em considerar como as preferências são formadas) é usada na sua justificativa. Uma razão mais 
convincente para considerar as preferências fixas é que esta premissa contribui para a simplicidade do modelo. Além de testes empíricos, os teóricos da escolha racional utilizam freqüentemente o critério da simplicidade para julgar as teorias rivais (por exemplo, Coleman, 1990, p. 19). No entanto, apesar de se poder sustentar que a simplicidade é desejável, esta não deve ser obtida a qualquer custo, especialmente se para isto for necessário adotar premissas empiricamente insustentáveis ou até falsas. Este é freqüentemente o caso com a teoria da escolha racional. Em algumas áreas da economia as preferências podem ser relativamente constantes, mas em muitas outras elas não o são. Assumir simplesmente que elas são constantes (e em alguns casos desprezar as evidências empíricas em contrário) representa falta de honestidade intelectual.

Mas a pressuposição que vai mais longe na teoria da escolha racional é a de que, diante das mesmas situações e assumindo as preferências constantes, existe um único "modo racional de agir", livre de qualquer especificação cultural. Por exemplo, os teóricos da escolha racional introduzem a noção de "convicção racional" sem levar em conta inteiramente que o contexto cultural no qual as pessoas se encontram afeta o que elas consideram ser ou não uma convicção fundada na razão. O problema com a teoria da escolha racional é que ela trabalha com convicções sobre a relação entre ação e resultado, o que necessariamente se apóia em noções culturalmente embebidas, por exemplo, com respeito a causalidade e ação social. É um erro reduzir a causalidade ou a ação social a apenas uma destas noções, como faz a teoria da escolha racional. Tomemos, por exemplo, duas pessoas: $A$ e $B$. Elas observam que a ação $x$ tende a ser seguida pelo resultado $y$. A pessoa $A$ tem uma noção de causalidade que leva em conta a regularidade, e a pessoa $B$ tem uma noção realista. A pessoa $A$ pode assumir que a observação é evidência suficiente (e necessária) para concluir que $x$ causa $y$, mas $B$ não fará o mesmo. Entretanto, seria errado dizer que a noção de $A$ é mais racional que a de $B$, ou vice-versa, simplesmente tendo como base as noções particulares de causalidade que $A$ e $B$ têm. Isto é especialmente verdadeiro considerando que, mesmo na literatura acadêmica, não há consenso sobre a superioridade de uma noção relativamente à outra (o que não quer dizer que $A$ ou $B$ não possam ter argumentos melhores para defender suas noções).

É importante mencionar que este segundo argumento pode também ser usado contra a teoria da decisão. Deixem-me relembrar o leitor que, como uma teoria normativa, a teoria da decisão indica o caminho racional de agir em uma situação específica, isto é, ela não parte do princípio de que as pessoas agem desta forma (e também não assume que as pessoas não agem desta forma). Minhas objeções prévias à teoria da escolha racional (o argumento contra o internalismo e o externalismo, o argumento contra a teorização a posteriori) não afetam a validade da teoria normativa. Porém, o argumento de que a teoria da escolha racional se apóia em uma noção equivocada de racionalidade, por considerá-la livre de especificações culturais, não ameaça apenas a teoria da escolha racional, mas também a teoria normativa.

\section{Conclusão}

Ao invés de sumariar os pontos já apresentados, organizo a linha de raciocínio de meus argumentos sugerindo o esboço de um quadro conceitual alternativo. Este quadro tem em comum com os teóricos da escolha racional a idéia de que as pessoas são capazes de visualizar de fora as condições fundamentais e as conseqüências de suas ações. Entretanto, minha perspectiva difere da teoria da escolha racional de várias formas.

Em primeiro lugar, considerando que a noção de uma racionalidade livre da cultura é altamente problemática, eu sugiro a noção mais cautelosa de "auto-reflexão de segunda ordem". Esta auto-reflexão de segunda ordem diz respeito à habilidade das pessoas em desenvolver conhecimento teórico com respeito às condições e efeitos e às regras e premissas fundamentais de suas ações, fenômenos tomados como dados pela teoria da escolha racional. Em oposição, "auto-reflexão de primeira ordem" refere-se às habilidades 
práticas compartilhadas mediante as quais as pessoas monitoram suas ação na vida diária. A comunicação comum, por exemplo, se baseia em auto-reflexão de primeira ordem. Partindo das atitudes dos outros, os indivíduos são capazes de refletir sobre formas alternativas de expressão. Dado que as regras fundamentais e premissas da gramática e do vocabulário da língua inglesa são compartilhados pelos indivíduos envolvidos, eles conseguem antecipar o significado de suas expressões para outros, conseguindo acompanhar uma conversação. Se, no entanto, eles refletirem teoricamente sobre as regras fundamentais da gramática ou do vocabulário, a autoreflexão de segunda ordem entra em jogo.

Em segundo lugar, contrariamente à visão internalista, a auto-reflexão de primeira ordem é comum, mas a autoreflexão de segunda ordem surge somente em algumas circunstâncias. A auto-reflexão pode aparecer porque as pessoas descobrem os efeitos não previstos de ações prévias ou porque encontram formas de vida diferentes. Ela pode também surgir a partir de mudanças nas preferências das pessoas ou devido a mudanças no ambiente, caso em que as práticas experimentadas anteriormente passam a ser consideradas fora de lugar com relação a desejos ou constrangimentos.

Em terceiro lugar, parece não fazer sentido afirmar que as práticas das pessoas são de forma geral racionais, no sentido da otimização ajustada ao ambiente. A visão de que existe uma, e apenas uma forma racional de agir é enganosa; além do que, a auto-reflexão de segunda ordem aparece somente em circunstâncias particulares. As pessoas não verificam continuamente a racionalidade de suas ações, fazendo isto apenas quando confrontadas com conseqüências não intencionais, como já destacado.

Em quarto lugar, a auto-reflexão de segunda ordem tornase especialmente significativa sociologicamente por adquirir características públicas e coletivas. Nestas circunstâncias, ela se torna a fonte potencial para a mudança deliberada ou para a estabilidade deliberada. $\mathrm{Na}$ ciência, por exemplo, a auto-reflexão coletiva de segunda ordem pode levar a uma mudança nas regras e nas premissas do paradigma. Da mesma forma, a reflexão coletiva dos trabalhadores sobre as condições estruturais de suas ações pode culminar em tentativas de "reestruturação". As novas práticas que são então introduzidas gradualmente se tornam latentes e parte integrante do conhecimento tácito, para serem questionadas apenas quando outras conseqüências não intencionais são encontradas.

Em quinto lugar, torna-se possível agora a criação de uma explicação alternativa para alguns dos sucessos empíricos da teoria da escolha racional. Suponhamos que uma certa prática (digamos, $P$ ) emergisse no interior de um grupo (digamos, G) como um resultado da auto-reflexão de segunda ordem no tempo $t_{1}$. Suponhamos também que, em $t_{2}, P$ tenha se tornado latente e seja parte do conhecimento prático de $G$. Finalmente, suponhamos que um observador tentasse dar sentido a $P$ em $t_{2}$. Caso as duas condições fossem satisfeitas - (a) o observador compartilhar um número de noções centrais de racionalidade com $G$ (por exemplo, o que torna racional uma certa convicção) e (b) as preferências de $G$ não mudarem drasticamente entre $t_{1}$ e $t_{2}$ (e tampouco os constrangimentos ambientais) —, o observador não teria muita dificuldade de atribuir algum tipo de racionalidade a estas práticas latentes em $t_{2}$. Isto explica por que os teóricos da escolha racional têm conseguido explicar especialmente os comportamentos das pessoas que têm padrões culturais similares aos seus e atuam em áreas da vida social nas quais as preferências e os constrangimentos são relativamente constantes.

\section{NOTAS}

1. Sérias objeções têm sido levantadas à reconstrução de Marx nesta direção (por exemplo, Cohen, 1982).

2. Estudiosos já familiarizados com a teoria da escolha racional talvez possam seguir para a próxima seção. 
3. Obviamente, quando existe incerteza, $P_{i}$ não pode ser calculado e, conseqüentemente, a utilidade esperada também é indeterminada.

4. Ver também Lawson (1989).

\section{BIBLIOGRAFIA}

ARROW, K. (1951), Social choice and individual values. New Haven, Yale University Press.

BECKER, G.C. (1976), The economic approach to buman behavior. Chicago, Chicago University Press.

BOUDON, R. (1982), Unintended consequences of social action. Londres, MacMillan.

BOURDIEU, P. (1977), Outline of a theory of practice. Cambridge, Cambridge University Press. . (1990), The logic of practice. Cambridge, Polity.

BROWN, R. (1965), Social psychology. Nova York, Free Press.

COHEN, G.A. (1982), "Reply to Elster on marxism: functionalism and game theory". Theory and Society, 11:483495.

COLEMAN, J. (1990), Foundations of social theory. Cambridge, Mass., Harvard University Press.

DOWNS, A. (1957), An economic theory of democracy. Nova York, Harper.

ELSTER, J. (1978), Logic and society; contradictions and posssible worlds. Chichester, John Wiley and Sons.

(1979), Ulysses and the sirens. Cambridge, Cambridge University Press.
(1983), Sour grapes: studies in the subversion of rationality. Cambridge, Cambridge University Press.

(1985), Making sense of Marx. Cambridge, Cambridge University Press.

(ed.). (1986a), Rational choice. Nova York, New York University Press.

(1986b), "Introduction", in J. Elster (ed.), Rational choice, Nova York, New York University Press, pp. 1-33.

(1989), Nuts and bolts for the social sciences. Cambridge, Cambridge University Press

FRIEDMAN, M. (1953), Essays in positive economics. Chicago, University of Chicago Press.

GREEN, D.P. e SHAPIRO, I. (1994), Pathologies of rational choice theory; a critique of applications in Political Science. New Haven, Yale University Press.

HARDIN, R. (1982), Collective action. Baltimore, Johns Hopkins University Press.

HINICH, M.J. (1981), "Voting as an act of contribution". Public choice, 36:135-140.

HOLLIS, M. (1988), The cunning of reason. Cambridge, Cambridge University Press. (1994), The philosophy of the social sciences. Cambridge, Cambridge University Press.

KEYNES, J.M. (1921), A treatise on probability. Londres, MacMillan.

KNIGHT, F. (1921), Risk, uncertainty and profit. Boston, Houghton Mifflin.

KREPS, D. (1990), Game theory and economic modelling. Oxford, Clarendon Press. 
LAWSON,T. (1989), "Abstraction, tendencies and stylised facts: a realist approach to economic analysis".Cambridge Journal of Economics, 13.

OLSON JR., M. (1965), The logic of collective action. Cambridge, Harvard University Press.

POSNER, R.A. (1980), "The ethical and political basis of the efficiency norm in commom law adjudication". Hofstra Law Review, 8: 487-551.

RIKER, W. e ORDERSHOOK, P.C. (1973), Introduction to positive political theory. Englewood Cliffs, Nova Jersey, Prentice Hall.

SARTRE, J.P. (1960), Critique de la raison dialectique. Paris, Gallimard.

SCHWARTZ, T. (1987), "Your vote counts on account of the way it is counted". Public Choice, 54: 101-121.

* Tradução de Eduardo Cesar Marques.

I N. do T. - Em diversos pontos do texto o autor incluiu expressões em francês, latim e alemão. Estas expressões foram deixadas de acordo com o original em inglês e grafadas em itálico. 